\title{
NATURAL ANTIOXIDANTS IN HENS' EMBRYOGENESIS AND ANTISTRESS DEFENCE IN POSTNATAL DEVELOPMENT (review)
}

\author{
P. Surai1, 2, V.I. Fisinin ${ }^{3}$ \\ ${ }^{1}$ Scottish Agricultural College (SAC), KA7 3BN, Scotland, Great Britain \\ ${ }^{2}$ Sumy National Agrarian University, Sumy 40021, Ukraine \\ e-mail:psurai@feedfoodco.uk \\ ${ }^{3}$ All-Russia Research and Development Institute of Poultry Breeding, RAAS, Sergiev Posad 141311, Russia \\ e-mail:fisinin@land.ru
}

Received November 26, 2012

Sum mary

\begin{abstract}
Evidence is accumulating indicating that a maternal diet can have a profound effect on the hatching egg quality and health status, growth and development of newly hatched chick. Several points are important to outline. Maternal diet determines chicken development during egg incubation and for the first few days post-hatch. Vitamin $\mathbf{E}$ and carotenoids accumulation in the chicken liver during embryonic development is considered as an adaptive mechanism to deal with stress conditions of the hatching process. In postnatal development a strategy of antioxidant defence is changed from antioxidant accumulation to the synthesis of antioxidant enzymes with more sophisticated and effective regulation at the gene level. Immune and digestive systems of the chicken are not mature at hatch and are actively developing during first 2 weeks post-hatch and are at risk of oxidative stress and need effective antioxidant protection. Increased vitamin E/carotenoid/Se supplementation of the maternal diet is proven to be beneficial for the embryonic and early postnatal development of the chick. However, maternal dietary manipulation is not able to prevent oxidative stress in early postnatal development and there is a need to address this issue. Therefore, a new antistress composition provided with drinking water is developed and successfully tested in commercial conditions of Ukraine and Russia.
\end{abstract}

Keywords: poultry, stress, antioxidants, emryogenesis, onthogenesis, vitamin E, carotenoids, Se, vitagenes, a new antistress composition.

The success of modern broiler industry is closely associated with breeding programs aimed at production of broiler chickens that show fast growth, high production yield, and efficient conversion of feed. These features of broilers often interfere with their health - as a rule, the higher is productivity, the more is birds' susceptibility to various stresses, which poses a certain problem for breeding work (1). From a fertilized egg cell to farm housing of chicks, there are various factors (quality of incubation eggs, egg storage conditions, incubation technology, conditions in the period between hatching and delivery to a farm), and their interaction notably affects productivity of reared broilers. In general, all of these factors are significant determinants of the quality of chicks (2). In contrast to mammals, avian embryogenesis occurs in an egg, the semi-closed system with only exchange of gases and water. Today it's a certainty that successful embryonic development of a chick depends on egg composition and conditions of incubation. Many facts from the available literature show that maternal diet is the main determinant of health and development of offspring in avians, as well as in humans and other mammals. Egg composition is such that it contains in yolk and albumen all the nutrients necessary for the development of future embryo (3). Polyunsaturated fatty acids (PUFA) and natural antioxidants of maternal diet are key important for the development of chick embryos and viability of chicks in early post-hatch period. Indeed, high content of endogenous antioxidants in the egg and embryonic tissues may be a major adaptive mechanism preventing the oxidative stress at hatching.

Free radicals: formation, biological functions and control. Free radicals are atoms, or molecules of any compounds containing unpaired electrons (one or more). Most of biologically important free radicals are formed in the presence of oxygen and nitrogen - activators of this process. Both these elements play a significant role in metabolism of human and animals, but under certain conditions they may pass (directionally or randomly) into the molecules of free radicals. Free radicals are highly unstable and very reactive; they can damage DNA, proteins, lipids, carbohydrates, and disrupt cell signaling system (4). DNA damage is associated with mutations, errors of genetic data transfer, impaired protein synthesis, and, in some cases, it leads to cancer. Protein damage causes disorders of ion transport, functioning of receptors, and it changes properties of certain most important enzymes. The oxidation of PUFA in cell membranes affects their structure and properties (fluidity and permeability, etc.), and the activity of membrane-bound enzymes. Damage to biological molecules causes a notable negative effect on growth, development, reproduction, and immunocompetence. In general, for the last three decades the study of free radicals and their adverse effects on biomolecules was mainly focused on lipid peroxidation as a basis of the observed adverse effects. The modern trend of such researches is associated with negative effects of free radicals on proteins and DNA $(5,6)$.

Cells are permanently attacked by free radicals, most of which are elements of a normal metabolism, or the agents of immune response in phagocytes that destruct microbes-invaders. Under normal physiological conditions, about 3-5\% of the oxygen utilized by cells and passed to the mitochondrial electron-transfer chain, may leave it to be converted into free radicals (7). In rats, each cell has to process daily about $10^{12} \mathrm{O}_{2}$ molecules, so $2 \%$ oxygen "leakage" contributes to about $2 \mathrm{~S} 10^{10}$ reactive molecules (free radicals) per cell daily. H.J. Helbock et al. (8) proved that in rats DNA of each cell daily interacts with about 100 million molecules of free radicals, and solely endogenous sources of DNA damage cause about 10 thousand potential mutagenic changes per cell (if not eliminated by its defenses) (9). Some types of nonrestorable oxidative damage accumulates with age. In old rats, it was observed about 66 thousand points of oxidative damage of the DNA per cell (10). B. Halliwell (11) showed that 1,3\% utilized oxygen can form peroxide radicals. In this case, it should be considered that the adult organism of $70 \mathrm{~kg}$ live weight at rest utilizes $3,5 \mathrm{ml} \mathrm{O}_{2} / \mathrm{kg}$ body weight per minute, or 352,8 liters of $\mathrm{O}_{2}$ (or $14,7 \mathrm{~mol}$ ) per day. Thus, if merely $1 \%$ of the utilized oxygen is converted to free radicals, this amounts to $0,147 \mathrm{~mol} / \mathrm{day}$, or about $1,72 \mathrm{~kg} / \mathrm{year}$. In stress, these values greatly increase. Along with free radicals formed in natural oxygen exchange, there are free radicals produced by cells of the immune system as anti-pathogenic agents (12). These calculations show that a great number of free radicals is daily formed in the organism, so thousands of biological molecules can be easily damaged if not protected. 
Natural antioxidants $(5,6,13-15)$. For most living organisms on the Earth, life without oxygen is impossible. Animals, plants, and many bacteria need oxygen for efficient conversion of energy. However, high content of oxygen in the atmosphere may be toxic. Survival in such conditions promoted evolution of living organisms during which they have developed specific mechanisms that protect cells from harmful effects of free radicals and their metabolites, and prevent accumulation of reactive oxygen species (ROS) or nitrogen species (RNS). The most important mechanisms form a single antioxidant system that includes various elements: natural fat-soluble antioxidants (vitamins $\mathrm{A}$ and $\mathrm{E}$, carotenoids, ubiquinones, etc.), water-soluble antioxidants (ascorbic acid, uric acid, taurine, etc.), antioxidant enzymes (glutathione - GSH-Px, catalase - CAT, and superoxide dismutase - SOD), thiol redox systems of glutathione (glutathione / glutathione reductase / glutaredoxin / glutathione peroxidase) and thioredoxin (thioredoxin / thioredoxin peroxidase / thioredoxin reductase).

Antioxidant substances are contained in cellular organelles, subcellular compartments or in an extracellular space; they provide a maximum protection of cells due to the multi-level antioxidant system. At the first level, formation of free radicals is prevented by elimination or inactivation of their predecessors, or inactivation of catalysts by antioxidant enzymes - SOD, GSH-Px, and CAT, as well as metal-binding proteins. Superoxide radicals are the main type of free radicals formed in cells under physiological conditions, so SOD (EC 1.15.1.1) is considered as the key element of the first level of antioxidant defense. This enzyme causes dismutation of superoxide radical:

$$
2 \mathrm{O}_{2} *+2 \mathrm{H}^{+} \stackrel{\mathrm{SOD}}{\longrightarrow} \mathrm{H}_{2} \mathrm{O}_{2}+\mathrm{O}_{2}
$$

The reaction product - hydrogen peroxide - is detoxified by GSH-Px and CAT enzymes to form water. Metal ions serve as catalysts that accelerate decomposition of lipid hydroperoxides to such cytotoxic products as aldehydes, alkoxyl and peroxide radicals. So, metal-binding proteins (transferrin, lactoferrin, haptoglobin, hemopexin, metallothionein, ceruloplasmin, ferritin, albumin, myoglobin, etc.) also perform the first level of antioxidant defense. It's a fact that iron and copper are strong stimulators of free radical reactions; therefore, availability of their free catalytic forms is strictly controlled in vivo. That's why living organisms are able to keep iron and copper securely in the form of metal-protein complexes (metalloproteins). This feature prevents catalytic activity of the metals and formation of hydroxyl radicals, which significantly reduces the damage of biomolecules.

Unfortunately, the first level of antioxidant defense can't completely terminate the formation of free radicals; some of them avoid detoxication and cause the reactions leading to damage of lipids, DNA and proteins. This necessitates the second level of antioxidant defense that enables antioxidants-terminators of oxidation chain reactions - vitamin E, coenzyme Q, carotenoids, vitamin A, ascorbic acid, uric acid, etc. Glutathione and thioredoxin systems are also important at this level of protection. These antioxidants strongly restrict the length and branching of free radical chains thereby preventing propagation of peroxidation reactions.

However, even the second level of antioxidant defense can't ensure reliable protection of lipids, proteins and DNA from damaging action of ROS and RNS. In this case, the third level of defense is activated. Systems of this level reduce the number of injured cells or restore damaged molecules; these are various enzymes - lipolytic (lipases), proteolytic (peptidases or proteases), and other (DNA restores, ligases, nucleases, polymerases, proteases, phospholipases, and various transferases).

All the abovementioned antioxidants function in close interconnection as elements of one integrated antioxidant system (16). Effective interactions of cell antioxidants are quite important for secure protection from free radicals and toxic products of their metabolism. For example, vitamin $\mathrm{E}$ is known as a major antioxidant in biomembranes and the hunting link of the antioxidant system. It is usually present in very low molar ratios (one molecule per two or three thousand molecules of phospholipids), and its deficit is hard to be supplied in the adult organism. Probably, this occurs due to the property of an oxidized vitamin E to turn to an active initial form through the reaction with other antioxidants (ascorbic acid, glutathione, ubiquinol, carotenoids). So, antioxidant defense of cells depends not only (and not so much) on quantity and occurrence of vitamin E, but rather on the efficiency of its recycling (Fig. 1) (17, $18)$.

Indeed, in the case of effective recycling of vitamin E, even small amount of it is sufficient to maintain reliable protection under normal physiological conditions. For example, avian embryonic brain contains very low level of vitamin E, while the contents of ascorbic acid and other substances involved in recycling of vitamin E are very high (19). Antioxidant protection of these tissues was found to be quite efficient and the products of lipid peroxidation in fresh tissue samples were not detected (20).

The idea of antioxidant recycling as a key mechanism of antioxidant defense is important for our progress in understanding of natural antistress protection. Thus, the degree of recycling of vitamin E radicals can affect both the efficiency of antioxidant mechanisms and the action time of vitamin E molecules in biological systems (Fig. 1).

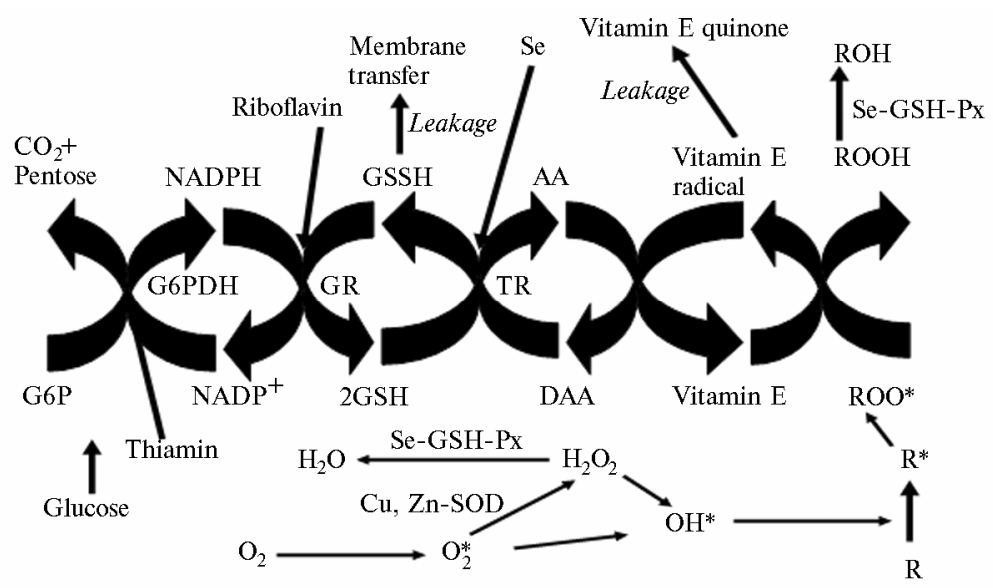

Fig. 1. Vitamin E recycling in the cell: G6P and G6PDH - glucose-6-phosphate and glucose-6-phosphate dehydrogenase, GSH-Px - glutathione peroxidase, GR - glutathione reductase, TR - thioreductase, SOD - superoxide dismutase, GSH and GSHH - glutathione oxidized and reduced, AA - ascorbic acid, DAA - dehydro-ascorbic acid.

So, antioxidant defense acts through the following mechanisms: reduce of oxygen content in biological systems; prevention 
of chain reactions by inactivation of primary radicals (SOD, GSH-Px, and catalase participate); binding of metal ions (metal-binding proteins); peroxides decomposition and conversion to non-toxic non-radical products (Se-GSH-Px); termination of free radical chains by absorption of intermediate metabolites such as peroxyl and alkoxyl radicals (vitamins E and C, glutathione, uric acid, ubiquinol, bilirubin, etc.); restoration and elimination of damaged molecules. There are also auxiliary mechanisms that maintain physiological balance under stress: recyclization; functioning of redox signaling system; expression of vitagenes with additional synthesis of important antioxidants (specific chaperone proteins, heat shock proteins, etc.) (21), and apoptosis that can remove damaged cells and limit mutagenesis.

The important feature of antioxidants is functioning in the body jointly as members of a single "antioxidant team" (Fig. 2). The role of each one is well known and closely interrelated with efficiency of other antioxidants. For example, the activity of vitamin $\mathrm{E}$ largely depends on the efficiency of its recycling (Fig. 1). Vitamin C provides the recycling of oxidized vitamin E and thus restores its activity, while glutathione performs the same with respect to vitamin $\mathrm{C}$. Vitamins $\mathrm{B}_{1}$ and $\mathrm{B}_{2}$ also participate the recycling of vitamin E. In the case of a balanced diet keeping sufficient amounts of antioxidants and substances involved in the recycling of vitamin E, even small doses of vitamin E are effective. However, during oxidative stress with enhanced formation of free radicals, natural reserves of an organism may be not enough to prevent the damage to major organs and systems. A possible solution of the problem is dietary supplementation with natural antioxidants, such as vitamin E, selenium, and carotenoids (Fig. 2). In such cases a lot depends on a specialist in poultry nutrition who makes a decision when and which measures must be provided considering their economical feasibility.

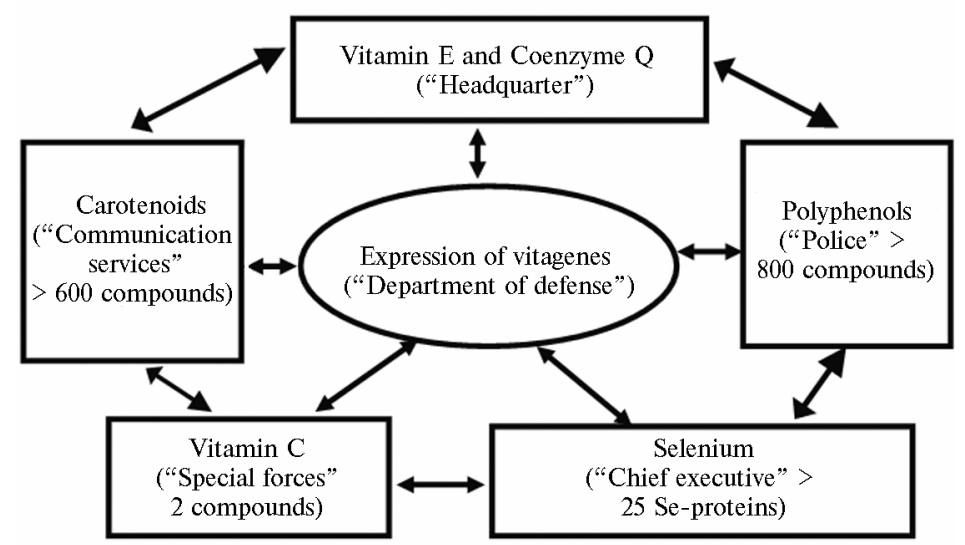

Fig. 2. The system of antioxidant defense ("antioxidant team") in animal cell.

Antioxidant defense of avian embryo $(5,13,14)$. In a newly hatched chick, the intensity of metabolism and oxygen consumption are greatly increased to provide endothermy during the transition from chorioallantoic respiration to pulmonary breathing (22). Such rapid transition may cause oxidative stress, which is prevented by effective antioxidant defense as a chick organism develops it by hatching. Along with it, lipids of avian embryonic tissues are enriched with polyunsaturated fatty acids highly sensitive to oxidation. So, a broad spectrum of antioxidant defenses is enabled in tissues of a hatchling - natural antioxidants (vitamin E, carotenoids, ascorbic acid, reduced glutathione, coenzyme Q, etc.) (19, 20, 23-25), enzymes (SOD-reductase, glutathione peroxidase, catalase) $(24,26)$, and mineral co-factors (selenium, zinc, manganese and iron) (19). Vitamin E, carotenoids, selenium, copper, manganese, and iron are provided by maternal contribution to an egg and a future chick, while other substances are synthesized in own tissues. Therefore, parental diet is the major factor predetermining the development of antioxidant system in avian embryo and newly hatched chicks. Dietary vitamin E, carotenoids, and mineral elements such as selenium, transfer to egg yolk and then to embryonic tissues. According to practical studies, increased content of these substances in parental diet significantly increases their contents in embryonic tissues and improves their resistance to lipid peroxidation (26-28).

This strategy of antioxidant defense changes in postnatal development of a chick. In a hatchling this is mainly provided by high tissue levels of natural antioxidants, especially vitamin E $(27,29)$, and sometimes (in wild birds), carotenoids (30-34). In the first 10 days after hatching, the levels of vitamin $\mathrm{E}$ and carotenoids in the liver tissue reduce by 20 times; this occurs in chickens, as well as in turkeys, ducks, and geese (23). Such reduce is compensated by significant increase of GSH-Px activity in the liver (26). So, the major factors of antioxidant defense in early postnatal development of birds are antioxidant enzymes and vitagenes providing effective adaptation of hatchlings to changed environment (21) and synthesis of the abovementioned enzymes at proper quantity, place, and time.

Vitamin E in egg yolk and embryonic tissues $(13,29)$. Vitamin E is one of the most important antioxidants that avian embryo obtains from egg yolk as accumulated component of parental diet. In birds, vitamin E plays several functions. For example, it is the main agent that terminates the oxidation chain being located in biomembranes and lipid droplets where lipid peroxidation occurs.

Vitamin E refers to a group of eight different natural forms that include both four tocopherols and four tocotrienols; $\alpha$ tocopherol has the greatest biological activity, while the role of the other compounds is mainly associated with protective properties in the gastrointestinal tract $(35,36)$. Vitamin $\mathrm{E}$ is absorbed in the small intestine, and the efficiency of this process depends on diet composition, dose, age, sex, and other individual characteristics of birds. Vitamin E accumulates in the liver and adipose tissue at a certain quantity though not enough for long-term needs. So, the amount of vitamin E transferred from a laying hen to each egg exceeds the liver reserve of this compound (13). At the same time, the liver of a laying hen contains as much accumulated vitamin A as more than 100 valuable eggs (13).

Crude vegetable oil is a rich source of vitamin E, which significantly reduces after refining. In poultry farming, dietary vitamin $\mathrm{E}$ is usually not considered at rationing, and so-called comprehensive supplements with high doses of vitamin $\mathrm{E}$ in premix provide a sufficient supply of this vitamin regardless of its content in feed.

Vitamin E is recommended for diets of broiler chickens (crosses Cobb, Ross, etc.) at a dose of $100 \mathrm{~g} / \mathrm{t}$ of mixed feed. It was proved that increased dose of vitamin E (250 g/t of feed) in the diet of laying hens relieves negative effects of heat stress $(27,37,38)$.

Vitamin $\mathrm{E}$ is unstable and easily oxidized. Commercial formulations generally contain esterified forms of vitamin $\mathrm{E}$ (e.g., 
tocopherol acetate) relatively stable in storage though not showing antioxidant activity unless converted to $\alpha$-tocopherol after digestion in the small intestine. Vitamin $\mathrm{E}$ is non-toxic and safe in use even at high doses. Market preparations of vitamin $\mathrm{E}$ are relatively expensive, so intense using it must be economically justified.

Vitamin E can easily transfer to the egg yolk and then - to the developing embryo (29). Eggs of many wild bird species have a relatively high content of this vitamin $(13,30,39)$. Accumulation of vitamin $\mathrm{E}$ in eggs is species-specific: feeding an equal dietary dose of vitamin E contributes to the higher level in chicken egg compared with eggs of turkeys, geese, or ducks (23).

The greatest accumulation of vitamin $\mathrm{E}$ in the liver was observed during hatching; this was assumed to be the evolutionary adaptation protecting a hatchling from oxidative stress at this critical period $(19,20)$. In the following 2 weeks after hatching this reserve will gradually and significantly (10-20 times) reduce due to metabolic demand (23).

Vitamin E accumulated in the egg determines the chick's status for this vitamin for at least a week after hatching (13, 19, 20). Therefore, increased content of vitamin $\mathrm{E}$ in parental diet ensures high content of this vitamin in the egg yolk and embryonic tissues, and good resistance of hatchlings to oxidative stress (27). The ability to efficient absorption of dietary vitamin E is yet undeveloped in new chicks, so they depend on its reserves obtained from parents (13). The alternative solution is watering in the first days of life the antistress supplement based on a water-soluble vitamin E compound $(40,41)$, which allows immediately supply the body reserves and provide antioxidant defense in this period most important for the development of birds' immune system and intestine.

However, dietary doses of vitamin $\mathrm{E}$ over $100 \mathrm{~g} / \mathrm{t}$ feed tested in conditions industrial chicken farms were found to be ineffective in terms of the improved hen's productivity and egg quality (13). In this regard, recent studies showed no differences in hatchability of eggs obtained from parental flocks who received the diets with vitamin E content of $15,150 \mathrm{or} 300 \mathrm{mg} / \mathrm{kg}$ feed (42), as well as 40,80 or $120 \mathrm{mg} / \mathrm{kg}$ feed (43).

Carotenoids in egg yolk and embryonic tissues (13, 31-34). Natural carotenoids were classified as antioxidants just not long ago. These yellow, orange, and red pigments were found in plants, insects, birds, and marine animals. Yellow or orange color of egg yolk is associated with carotenoids. They function in the body as the part of antioxidant defense involved in recycling of other antioxidants including vitamin E (13).

Egg yolk easily accumulates carotenoids which then transfer to the developing embryo $(33,34)$ In embryogenesis, a part of these reserves is utilized in metabolic processes such as antioxidant defense. Many wild bird species can accumulate in the egg yolk great amounts of carotenoids (50-10 times more than in edible chicken eggs) (30, 39). Eggs from the hens fed a maize-based diet were found to contain at least twice more carotenoids than eggs from the hens given a wheat-barley diet (44).

Carotenoids are involved in many biochemical processes and provide various physiological functions; e.g., their pronounced immunomodulatory properties allow to maintain bird's health (45). According to the author's studies, carotenoid-associated bright coloration of feathers in males of some wild species indicates their health, in particular, high immunocompetence (46).

Animals' need in carotenoids is not yet measured. Many plant foods are rich in carotenoids, while their content in food products of animal origin is very low. Carotenoids are instable and rapidly oxidized during storage of fodder. Natural body reserves of carotenoids are limited.

In avian embryogenesis, carotenoids intensely transfer from the egg yolk to the developing embryo, which accumulates their maximum content in the liver by hatching. Like vitamin E, this tissue reserve is necessary for adaptation to stress associated with hatching $(20,33,34)$, and after it the liver content of carotenoids rapidly declines (23). Hatchlings from carotenoid-deficient eggs have less ability to utilize carotenoids from feed than chicks from the eggs with rich content of carotenoids (47, 48). Increasing the dose of carotenoids in parental diet correlates with intense accumulation of vitamin $\mathrm{E}$ in the egg yolk, embryonic tissues and better resistance of hatchling in conditions of oxidative stress (28).

Canthaxanthin has a special place among over 750 known carotenoids as antioxidant with many other biologically important properties. High antioxidant activity of this carotenoid was shown in different model systems in vitro, as well as in experimental animals in vivo. In the Scottish Agricultural College, the authors studied the effect of canthaxanthin added to diets of breeding poultry (28). The control group of chickens was fed the basic diet with total content of xanthophylls $2 \mathrm{mg} / \mathrm{kg}$ feed. The experimental groups received the same diet supplemented with canthaxanthin at various doses $(3,6,12$ and $24 \mathrm{mg} / \mathrm{kg})$, the result of which was a notable dose-dependent accumulation of carotenoids in the egg yolk. It showed a gradual change in color from pale yellow in the control group to dark red in birds given $24 \mathrm{mg} / \mathrm{kg}$ canthaxanthin. The significant fact was established: canthaxanthin stimulates accumulation of vitamin $\mathrm{E}$ in the developing chicks. High levels of canthaxanthin and vitamin E accumulated in the liver of new chicks (both 1-dayold and 7-day-old) notably reduced susceptibility of the tissue to lipid peroxidation. This research has shown that parental diet is the main factor determining carotenoid status of their offspring for at least 7 days after hatching. Antioxidant defense of chicks can be improved by dietary supplementation of their parents, which opens up new opportunities for the poultry industry. For hatchlings, early postnatal life is the critical period for development of major physiological systems, including the immune system, and these processes are often complicated by oxidative stress (13). Thus, increasing the contents of carotenoids, particularly canthaxanthin, in parental diet is a helpful measure that supports efficient antioxidant defenses and high viability of chicks.

A favorable effect of canthaxanthin (CX) supplements in the diets of breeding hens was then confirmed by Chinese researchers (49). In their experiments, laying hens for 24 weeks were fed the basic diet and the same diet with $\mathrm{CX}(6 \mathrm{mg} / \mathrm{kg}$ feed). Canthaxanthin significantly improved pigmentation of egg yolks according to Roche egg yolk fan $(\mathrm{P}<0,001)$ showing the effective transfer of dietary CX to egg yolks. Improved antioxidant status of CX-rich yolks compared with yolks of ordinary eggs $(\mathrm{P}<0,05)$ was observed in the content of malondialdehyde (MDA): $86,92 \mathrm{vs} .139,83 \mathrm{nmol} / \mathrm{g}(\mathrm{P}=0,023)$, as well as total antioxidant capacity 3,16 vs. $1,87 \mathrm{U} / \mathrm{g}(\mathrm{P}<0,001)$. In hatchlings, the studied parameters were significantly better $(\mathrm{P}<0,05)$ if their parents received the diet with CX. In 1-day-old experimental chicks, the blood level of MDA was much lower than in the control group (2,61 vs. 4,28 nmol/g; $\mathrm{P}<0,001)$, and higher activity of SOD (144,7 vs. 98,4 U/ml, $\mathrm{P}<0,05)$. Feeding CX to parental flock was also beneficial for total antioxidant capacity of hatchlings (33\% increase from 13,8 to $18,3 \mathrm{U} / \mathrm{ml} ; \mathrm{P}=0,052)$.

An industrial experiment (50) demonstrated the effect of canthaxanthin added to the diet of breeding hens the cross Ross (6 $\mathrm{mg} / \mathrm{kg}$ ) on antioxidant status of their offspring. The 1-day-old experimental hatchlings had significantly higher antioxidant activity of the blood serum and much lower lipid peroxidation compared with control, as well as reduce in mortality (0 vs. $4 \%)$ during the first 3 weeks (21 days) after hatching. So, it was proved in vivo that canthaxanthin in parental diet improves protection of tissues in hatchlings under oxidative stress, which fact can be quite important for poultry breeding.

Another experiment showing the role of $\mathrm{CX}$ in parental diet of chickens was conducted in Brazil (51). CX was found to 
reduce lipid peroxidation in yolks of stored incubation eggs laid by hens whose diet was supplemented with CX. It also reduced oxidation in fresh eggs ( $\mathrm{P}<0,05)$, and the eggs stored for 4 days $(\mathrm{P}<0,001), 8$ days $(\mathrm{P}<0,001)$, and 12 days $(\mathrm{P}<0,0001)$. In this study, $\mathrm{CX}$ stimulated increased egg production in certain periods, though with no reliable differences between two groups in general.

This research has revealed the positive effect of CX in parental diet on egg viability, hatchability and prevention of embryonic mortality. In the experimental group, the proportion of viable (fertilized) eggs was 92,1 vs. $91,0 \%$ in control ( $\mathrm{P}<0,02$ ), hatchability - 93,7 vs. 91,3\% ( $\mathrm{P}=0,0003)$, embryonic mortality $-3,7$ vs $5,5 \%(\mathrm{P}<0,003)$, and, as a result, significantly better outcome of hatchlings $(86,2$ vs. $83,0 \% ; \mathrm{P}=0,0001)$. Along with it, $\mathrm{CX}$ effectively prevented embryonic mortality in different periods of embryogenesis: in the first 48 hours $(1,04 \%$ vs. 1,$80 ; \mathrm{P}=0,008)$ and the $15^{\text {th }}-21^{\text {st }}$ days of incubation $(1,44 \mathrm{vs} 2,07 \% ; \mathrm{P}=0,017)$. In this study, $\mathrm{CX}$ added to the diet of laying hens increased $(\mathrm{P}=0,0171)$ the proportion of fertilized eggs (probably due to better survival and preservation of sperm in the reproductive tract of hens). This allows to draw a parallel with the study of astaxanthin (AX) another carotenoid similar in structure to canthaxanthin and also tested as feed supplement for laying hens; it also transfers to the egg yolk and reliably preserves good hatchability of stored incubation eggs (52). In this report, hatchability of eggs stored at $21{ }^{\circ} \mathrm{C}$ was reliably lower than of those stored at $10{ }^{\circ} \mathrm{C}$, while increasing AX content in the diet of laying hens from 5 to $20 \mathrm{mg} / \mathrm{kg}$ gradually restored hatchability of eggs even after storage at $21^{\circ} \mathrm{C}$.

Selenium in egg yolk and embryonic tissues of birds $(5,13,53-56)$. Selenium is a component of selenoproteins, such as glutathione peroxidase (GSH-Px), thioredoxin (TrxR), iodothyronine deiodinase (ID) and some others. In general, there are 25 selenoproteins identified in humans and animals by now.

Food products and feed ingredients have different contents of selenium, commonly very low. Physiological need in selenium is small, but if not supplied, this deficit suppresses the antioxidant system and general state of health. High doses of selenium are toxic, but such critical levels are 10-20 times higher than its actual dietary content.

The main sources of selenium for poultry are various selenium-containing amino acids, the main of which is selenomethionine (Se-Met), as well as inorganic compounds - selenites or selenates. According to studies of recent years, organic selenium compounds are more effective, but such additives are still expensive. Sodium selenite is known as a so-called rapid response remedy that stimulates rapid synthesis of selenoproteins in the case of selenium deficiency. However, selenium of the selenite can't be reserved in the organism and must be supplied continuously. On the contrary, selenomethionine that can be accumulated in tissues at dietary introduction, but the synthesis of selenoproteins in response to Se-Met is somewhat delayed. The new concept of antistress strategy $(21,57-65)$ based on watering antistress additives containing the optimal ratio of both these selenium compounds allows to resolve the dilemma between cost and effect of selenium supplements in poultry (at least in growing broilers and laying hens): immediate watering the drug under stress instead of a long-term feeding Se-Met ensuring its accumulation of in the organism.

The amount of selenium in the egg white and yolk depends on its dietary content and source compound. Distribution of selenium in organs and tissues: liver $>$ kidneys $>$ spleen $>$ heart muscle $>$ egg $>$ blood $>$ breast muscles (regardless of dose and source of selenium). Maternal contribution of selenium positively affects accumulation of this element in embryonic tissues of chicks and determines their selenium status at hatching and next few days (66).

In recent years it was obtained some evidence that selenium accumulated in the egg may affect expression of genes determining embryogenesis and development of antioxidant system of chicks.

Other antioxidants. Ascorbic acid is synthesized in the organism of chicks and not contained in eggs, so its effect on the quality of incubation eggs is questionable. Experimental data (67) suggest that ascorbic acid added to the diet of lying hens didn't influence their productivity. However, under stress, this supplement can be useful. In the proposed strategy of antistress defense, ascorbic acid and other important antistress substances are combined in one complex antistress composition (21).

L-carnitine is another compound with antioxidant properties. Feeding it to a parental flock improves the carcass quality in offspring. In particular, using L-carnitine as feed supplement to laying hens contributed to reduced fat content and increased weight of breast muscle in the offspring grown on high-nutritious diet (68). Along with it, eggs from these hens exhibited increased content of L-carnitine in the egg yolk $(P=0,001)$, lower weight of yolk sac in hatchlings $(P=0,0001)$, and reduced content of lipids in the yolk sac at hatching $(\mathrm{P}=0,01)$, as well as the changed composition of fatty acid in the yolk sac (69). So, it was reasonable to include Lcarnitine in the antistress formulation (70).

There were also some attempts to improve the quality of incubation eggs by feeding to parental flock various plant extracts, essential oils and some other components with antioxidant properties in vitro, but it's too early to make conclusions on their efficiency.

Antioxidants and stress $(5,13,14,21)$. This review shows that high doses of vitamin E, carotenoids, and selenium added to the diet of laying hens can protect hatchlings from oxidative stress in early postnatal period. At the same time, these means just partially help to overcome adverse effects of such stresses.

Vitagenes are in focus of the new promising concept actively developed in recent years; these specific genes are involved in adaptation to adverse environmental conditions. Earlier, the authors reviewed this issue in detail (21), as well as prospects for use of the new antistress drug that affects expression of vitagenes by various bioactive substances. Testing this drug in vitro has proved its positive effect on early postnatal development of chicks and prevention of oxidative stress associated with undeveloped digestive system $(40,41)$. The proposed concept can help to develop effective methods against forage-related disorders, including those caused by mycotoxins $(60,61)$, ochratoxin A $(62,63)$, and T-2 toxin $(64,65)$, as well as to provide high immunocompetence of poultry under stress (57). This antistress drug was also found to be effective in other stresses (71-73) and it improved the egg shell quality (72). The proposed concept was also successfully used in pig farming (74): using the developed antistress composition was highly efficient in piglets at weaning stress (75).

So, the extensive experimental data show that parental diet predetermines the quality of incubation eggs and hatchlings their health, growth and development; in particular, it affects the development of chicks during incubation and in the first few days after hatching. Vitamin E and carotenoids accumulated in the liver of chicks in embryogenesis are involved in adaptation to hatching stress. In postnatal development, the strategy of anti-oxidant defense changes from a simple accumulation of antioxidants to the more complex, rapid and effective level of gene regulation through the synthesis of antioxidant enzymes. Immune and digestive systems of newly hatched chicks are immature; they develop in the first 2 weeks of life, and this critical period is often complicated by oxidative stress and need in effective antioxidant defense. In this case, high content of vitamin E, carotenoids, and selenium added to parental diet as feed supplements provide a beneficial effect on embryogenesis and early postnatal development of chicks. To ensure the 
efficient antioxidant defense of hatchlings in early period of life, it is recommended to use the new antistress drug for watering to chickens that improves their growth and development; beneficial effect of this composition was proved by practice of many poultryfarming and pig-farming enterprises abroad.

\section{REFERENCES}

1. Siegel P.B., Price S.E., Meldrum B., Picard M., Geraert P.A. Performance of pureline broiler breeders fed two levels of vitamin E. J. Poult. Sci., 2001, 80: 12581262 .

2. Decuypere E., Tona K., Bruggeman V., Bamelis F. The day-old chick: a crucial hinge between breeders and broilers. World's Poult. Sci. J., 2001, 57: 127-138.

3. Speake B.K., Murray A.M.B., Noble R.C. Transport and transformation of yolk lipids during development of the avian embryo. Progr. Lipid Res., 1998, 37: 1-32. 4.

Halliwell B. Free radicals and antioxidants: updating a personal view. Nutr. Rev., 2012, 70: 257-265.

5. Surai P.F. Selenium in nutrition and health. Nottingham University Press, Nottingham, UK, 2006.

6. Surai P.F., Pappas A.C., Karadas F., Papazyan T.T., Fisinin V.I. Selenium enigma: Health implications of an inadequate supply. In: Moden dietary fat intakes in disease promotion /F. De Meester, S. Zibadi, D.R. Watson (eds.). Humana Press, Springer, NY, 2010: 379-403.

7. Singal P.K., Khaper N., Palace V., Kumar D. The role of oxidative stress in the genesis of heart disease. Cardiovascular Res., 1998, 40: 426-432.

8. Helbock H.J., Beckman K.B., Shigenaga M.K., Walter P.B., Woodall A.A., Yeo H.C., Ames B.N. DNA oxidation matters: the HPLC-electrochemical detection assay of 8-oxo-deoxyguanosine and 8-oxo-guanine. PNAS USA, 1998, 95: 288-293.

9. Ames B.N., Gold L.S. The causes and prevention of cancer: gaining perspective. Environ. Health Perspect., 1997, 105 (Suppl 4): 865-873.

10. Ames B.N. An enthusiasm for metabolism. J. Biol. Chem., 2003, 278: 4369-4380.

11. Halliwell B. Free radicals and antioxidants: a personal view. Nutr. Rev., 1994, 52: 253-265.

12. Kettle A.J., Winterbourn C.C. Myeloperoxidase: a key regulator of neutrophil oxidant production. Redox Report, 1997, 3: 3-15.

13. Surai P.F. Natural antioxidants in avian nutrition and reproduction. Nottingham University Press, Nottingham, UK, 2002.

14. Surai P.F. Minerals and anti-oxidants. In: Re-defining mineral nutrition /J. Taylor-Pickard, L.A. Tucker (eds.). Nottingham University Press, Nottingham, UK, 2005: 147-177.

15. Surai P.F., Fisinin V.I Ill health effects of food lipids: consequences of inadequate food processing, storage and cooking. In: Modern dietary fat intakes in disease promotion /F. De Meester, S. Zibadi, D.R. Watson (eds.). Humana Press, Springer, NY, 2010: 251-274.

16. Fisinin V.I., Surai P.F., Papazyan T.T. Zhivotnovodstvo Rossii, 2008, 1: 57-58

17. Papazyan T.T., Fisinin V.I., Surai P.F. Ptitsa i ptitseprodukty, 2009, 1: 37-39.

18. Papazyan T.T., Fisinin V.I., Surai P.F. Ptitsa i ptitseprodukty, 2009, 2: 21-24.

19. Surai P.F., Speake B.K., Noble R.C., Sparks N.H.C. Tissue-specific antioxidant profiles and susceptibility to lipid peroxidation of the newly hatched chick. Biology Trace Element Research, 1999, 68: 63-78.

20. Surai P.F., Noble R.C., Speake B.K. Tissue-specific differences in antioxidant distribution and susceptibility to lipid peroxidation during development of the chick embryo. Biochim. Biophys. Acta, 1996, 11(1304/1): 1-10.

21. Surai P.F., Fisinin V.I. Sel'skokhozyaistvennaya Biologiya [Agricultural Biology], 2012, 4: 3-13.

22. Hohtola E., Visser G.H. Development of locomotion and endothermy in altricial and precocial birds. In: Avian growth and development: evolution within the altricial-precocial spectrum/J.M. Starck, R.E. Ricklefs (eds.). Oxford University Press, Oxford, 1998: 157-173.

23. Surai P., Ionov I., Kuchmistova E., Noble R., Speake B. The relationship between the levels of a-tocopherol and carotenoids in the maternal feed, yolk and neonatal tissues: comparison between the chicken, turkey, duck and goose. J. Sci. Food Agricult., 1998, 76: 593-598.

24. Surai P.F. Tissue-specific changes in the activities of antioxidant enzymes during the development of the chicken embryo. Br. Poult. Sci., 1999 , $40: 397-405$.

25. Karadas F., Surai P.F., Sparks N.H. Changes in broiler chick tissue concentrations of lipid-soluble antioxidants immediately post-hatch. Compar. Biochem. Physiol.

A. Mol. Integr. Physiol., 2011, 160: 68-71.

26. Surai P.F. Effect of the selenium and vitamin E content of the maternal diet on the antioxidant system of the yolk and the developing chick. Br. Poult. Sci., 2000, 41: 235-243.

27. Surai P.F., Noble R.C., Speake B.K. Relationship between vitamin E content and susceptibility to lipid peroxidation in tissues of the newly hatched chick. Br. Poult. Sci., 1999, 40: 406-410.

28. Surai A.P., Surai P.F., Steinberg W., Wakeman W.G., Speake B.K., Sparks N.H.C. Effect of canthaxanthin content of the maternal diet on the antioxidant system of the developing chick. Br. Poult. Sci., 2003, 44: 612-619.

29. Surai P. Vitamin E in avian reproduction. Poult. Avian Biol. Rev., 1999, 10: 1-60.

30. Surai P.F., Bortolotti G.R., Fidgett A., Blount J., Speake B.K. Effects of piscivory on the fatty acid profiles and antioxidants of avian yolk: studies on eggs of the gannet, skua, pelican and cormorant. J. Zool. Lond., 2001, 255: 305-312.

31. Surai P.F. The antioxidant properties of canthaxanthin and its potential effects in the poultry eggs and on embryonic development of the chick. Part 1 . World's Poult. Sci. J., 2012, 68: 465-475.

32. Surai P.F. The antioxidant properties of canthaxanthin and its potential effects in the poultry eggs and on embryonic development of the chick. Part 2 . World's Poult. Sci. J., 2012, 68: 717-726.

33. Surai P.F., Speake B.K., Sparks N.H.C. Carotenoids in avian nutrition and embryonic development. 1. Absorption, availability and levels in plasma and egg yolk. $J$ Poult. Sci., 2001, 38: 1-27.

34. Surai P.F., Speake B.K., Sparks N.H.C. Carotenoids in avian nutrition and embryonic development. 2. Antioxidant properties and discrimination in embryonic tissues. J. Poult. Sci., 2001, 38: 117-145.

35. Surai K.P., Surai P.F., Speake B.K., Sparks N.H.C. Antioxidant-prooxidant balance in the intestine: food for thought. 2 . Antioxidants. Current Topics in Neutraceutical Research, 2004, 2: 27-46.

36. McLean J.A., Karadas F., Surai P.F., Speake B.K., McDevitt R.M., Sparks N.H.C. Lipid-soluble and water-soluble antioxidant activities of the avian intestinal mucosa at different sites along the intestinal tract. Compar. Biochem. Physiol., 2005, 141B: 366-372.

37. Bollengier-Lee S., Williams P.E., Whitehead C.C. Optimal dietary concentration of vitamin E for alleviating the effect of heat stress on egg production in laying hens. Br. Poult. Sci., 1999, 40: 102-107.

38. Whitehead C.C., Bollengier-Lee S., Mitchell M.A., Williams P.E. Vitamin E can alleviate the depressed egg production of heat-stressed laying hens. Br. Poult. Sci., 1998 Dec, 39(Suppl): S44-S46.

39. Garamszegi L.Z., Biard C., Eens M., Moller A.P., Saino N., Surai P. Maternal effects and the evolution of brain size in birds: overlooked developmental constraints. Neuroscience and Biobehavioral Reviews, 2007, 31: 498-515.

40. Fisinin V.I., Surai P.F. Ptitsevodstvo, 2012, 2: 11-15.

41. Fisinin V.I., Surai P.F. Ptitsevodstvo, 3: 9-12

42. Biswas A., Mohan J., Sastry K.V.H. Effect of vitamin E on production performance and egg quality traits in Indian native Kadaknath hen. Asian-Aust. J. Anim. Sci., 2010, 23: 396-400

43. Tsai H.L., Chang S.K.C., Lin Y.F., Chang S.J. Beneficial effects of maternal vitamin E supplementation on the antioxidant system of the neonate chick brain. Asian-Aust. J. Anim. Sci., 2008, 21: 225-231.

44. Surai P.F., Sparks N.H.C. Comparative evaluation of the effect of two maternal diets on fatty acids, vitamin E and carotenoids in the chick embryo. Br. Poult. Sci., 2001, 42: 252-259.

45. Moller A.P., Biard C., Blount J.D., Houston D.C., Ninni P., Saino N., Surai P.F. Carotenoid-dependent signals: indicators of foraging efficiency, immunocompetence or detoxification ability? Poult. Avian Biol. Rev., 2000, 11: 137-159.

46. Blount J.D., Metcalfe N.B., Birkhead T.R., Surai P.F. Carotenoid modulation of immune function and sexual attractiveness in Zebra Finches. Science, 2003, 300: $125-127$.

47. Koutsos E.A., Clifford A.J., Calvert C.C., Klasing K.C. Maternal carotenoid status modifies the incorporation of dietary carotenoids into immune tissues of growing chickens (Gallus gallus domesticus). J. Nutr., 2003, 133: 1132-1138.

48. Koutsos E.A., García López J.C., Klasing K.C. Maternal and dietary carotenoids interactively affect cutaneous basophil responses in growing chickens (Gallus gallus domesticus). Compar. Biochem. Physiol. B. Biochem. Mol. Biol., 2007, 147: 87-92.

49. Zhang W., Zhang K.Y., Ding X.M., Bai S.P., Hernandez J.M., Yao B., Zhu Q. Influence of canthaxanthin on broiler breeder reproduction, chick quality, and per- 
formance. J. Poult. Sci., 2011, 90: 1516-1522.

50. Robert F., Panheleux-Le Bastard M., Hamelin C., Boulard C. Effect of canthaxanthin supplementation in the ROSS breeder diet on oxidative stress in chick. Proc. 16th European Symposium on Poultry Nutrition. France, 2008: 731-734.

51. Rosa A.P., Scher A., Sorbara J.O.B., Boemo L.S., Forgiarini J., Londero A. Effects of canthaxanthin on the productive and reproductive performance of broiler breeders. Poult. Sci., 2012, 91: 660-666.

52. Saito F., Kita K. Maternal intake of astaxanthin improved hatchability of fertilized eggs stored at high temperature. J. Poultry. Sci., 2011, 1: 33-39.

53. Surai P.F. Selenium in poultry nutrition: a new look at an old element. 1. Antioxidant properties, deficiency and toxicity. World's Poult. Sci. J., $2002,58: 333-347$.

54. Surai P.F. Selenium in poultry nutrition: a new look at an old element. 2. Reproduction, egg and meat quality and practical applications. World's Poult. Sci. J., 2002, 58: 431-450.

55. Surai P.F., Karadas F., Pappas A.C., Sparks N.H. Effect of organic selenium in quail diet on its accumulation in tissues and transfer to the progeny. Br. Poult. Sci., 2006, 47: 65-72

56. Fisinin V.I., Papazyan T.T., Surai P.F. Selenium in poultry nutrition. In: Current advances in selenium research and application /P.F. Surai, J.A. Taylor-Pickard (eds.). Wageningen Academic Publishers, The Netherlands, 2008: 221-261.

57. Fisinin V.I., Surai P.F. Zhivotnovodstvo segodnya, 2011, 9: 40-47.

58. Fisinin V.I., Surai P.F. Ptitsa i ptitseprodukty, 2011, 5: 23-26.

59. Fisinin V.I., Surai P.F. Ptitsa i ptitseprodukty, 2011, 6: 10-13.

60. Fisinin V.I., Surai P.F. Zhivotnovodstvo Rossii, 2012, 5: 11-14.

61. Fisinin V.I., Surai P.F. Zhivotnovodstvo Rossii, 2012, 6: 3-5.

62. Fisinin V.I., Surai P.F. Kombikorma, 2012, 3: 55-60.

63. Fisinin V.I., Surai P.F. Kombikorma, 2012, 5: 59-60.

64. Fisinin V.I., Surai P.F. Ptitsa i ptitseprodukty, 2012, 3: 38-41.

65. Fisinin V.I., Surai P.F. Ptitsa i ptitseprodukty, 2012, 4: 36-39.

66. Pappas A.C., Karadas F., Surai P.F., Speake B.K. The selenium intake of the female chicken influences the selenium status of her progeny. Compar. Biochem. Physiol., 2005, 142B: 465-474.

67. Creel L.H., Maurice D.V., Lightsey S.F., Grimes L.W. Stability of dietary ascorbic acid and the effect of supplementation on reproductive performance of broiler breeder chickens. Br. Poult. Sci., 2001, 42: 96-101

68. Kidd M.T., McDaniel C.D., Peebles E.D., Barber S.J., Corzo A., Branton S.L., Woodworth J.C. Breeder hen dietary L-carnitine affects progeny carcase traits. Br. Poult. Sci., 2005, 46: 97-103.

69. Zhai W., Neuman S.L., Latour M.A., Hester P.Y. The effect of male and female supplementation of L-carnitine on reproductive traits of white leghorns. J. Poult. Sci., 2008, 87: 1171-1181.

70. Surai P.F., Fotina T.I. Effektivnoye ptitsevodstvo, 2010, 8: 19-25.

71. Surai P.F., Boroday V.P. Suchasne ptahivnitstvo, 2010, 7-8: 31-35.

72. Surai P.F., Fotina T.I. Korma i fakty, 2010, 4: 6-10.

73. Surai P.F. Korma i fakty, 2012, 2: 7-8.

74. Surai P.F., Me'lnichuk S.D. Svinovodstvo Ukrainy, 2012, 2: 10-15.

75. Gaponov I.V., Fotina T.I., Surai P.F. Svinovodstvo Ukrainy, 2012, 6: 6-9. 